\title{
Assessment of Clients Satisfaction in Family Planning Service Delivery in Port Harcourt, Nigeria
}

\author{
Emmanuel Okwudili Oranu*, Ijeoma Chioma Oppah \\ Department of Obstetrics and Gynaecology, University of Port Harcourt Teaching Hospital, Port Harcourt, Nigeria \\ Email: *meetemma24@gmail.com, *emmanuel.oranu@uniport.edu.ng
}

How to cite this paper: Oranu, E.O. and Oppah, I.C. (2020) Assessment of Clients Satisfaction in Family Planning Service Delivery in Port Harcourt, Nigeria. Journal of Biosciences and Medicines, 8, 88-99. https://doi.org/10.4236/jbm.2020.88009

Received: May 29, 2020

Accepted: August 15, 2020

Published: August 18, 2020

Copyright (๑) 2020 by author(s) and Scientific Research Publishing Inc. This work is licensed under the Creative Commons Attribution International License (CC BY 4.0).

http://creativecommons.org/licenses/by/4.0/

\section{(c) (i) Open Access}

\begin{abstract}
Background: Client satisfaction is considered as one of the desired outcomes of health care service delivery and it is directly related to the utilization of any health services. The family planning clinic remains one of the important health care delivery outlets where client satisfaction guarantees continuation of usage, hence this study. Objective: The objective of this study is to assess the determinants of client satisfaction with the family planning (FP) services provided in Port Harcourt. Materials and methods: This was a descriptive prospective cross-sectional study conducted between $18^{\text {th }}$ of June 2018 and $18^{\text {th }}$ of July 2018 . The target population is women of reproductive age group (15 - 49) who visited 11 randomly selected family planning health facilities in Port Harcourt during the study period. A set of exit interviewer-administered questionnaire (pretested for reliability and validity) was used for data collection from a sample size of 195 respondents; and analyzed using SPSS 22.0. Standard deviation was used for continuous variable while categorical variables were presented in simple percentages and frequencies. The $\mathrm{P}$ value was set at $<0.05$ and confidence interval was $95 \%$. Results: Age range 30 - 39 years constituted the largest proportion of $51.3 \%$. A large proportion of the women (87.2\%) expressed satisfaction with FP services provided. All respondents said the facilities were easily accessible, clean and were treated respectfully. However, only about half of the clients $(51.3 \%)$ received their chosen contraceptive product after 1 hour. Conclusion: A huge proportion of family planning clients expressed satisfaction with family planning service delivery in Port Harcourt; not minding the longer waiting time. Implication of this is continued use and by implication improved contraceptive prevalence.
\end{abstract}

\section{Keywords}

Family Planning Service Delivery, Client Satisfaction, Port Harcourt 


\section{Introduction}

Patients have the right to expect quality care in services delivered. Providing quality care in family planning services is an important task for the health care providers so as to maintain and increase service utilization [1]. The availability and increasing quality of family planning services are believed to have contributed to the increased contraceptive prevalence and declining fertility rates in developing countries [2].

The sub-Saharan Africa records the highest rate of maternal mortality in the world (as high as 1 maternal death per 100 births) [3]. Due to the low prevalence of contraceptive use, the rate of unintended pregnancies is high and as many as $50 \%$ of these unintended pregnancies end up in elective abortions. Since abortion in Sub-Saharan African is not on demand, most of these abortions are therefore performed under unsafe and secretive conditions, with approximately $25 \%$ of them resulting in serious complications and account for $20 \%-40 \%$ of maternal death [3].

Family planning methods protect women from unintended pregnancies, thus reducing the number of unwanted pregnancies and subsequent abortions that may result [4]. It then follows, that if unwanted/unplanned pregnancies were prevented in Sub-Saharan Africa, maternal mortality rates will reduce by $25 \%$ [5]. To this effect, improved quality of care is an increasingly important goal of international family planning programs. All clients, no matter their social status, deserve courteous treatment, correct information, and reliable products. Evidence suggests that providing such quality services will lead to increased service utilization by new and continued users and eventually result in higher contraceptive prevalence and lower fertility [6].

Assessment of the Family planning client satisfaction on service delivery in health facilities is receiving growing attention as a strategy for monitoring and evaluation of primary health care program in developing countries [7] [8]. Good quality family planning service helps individuals and couples meet their reproductive health needs safely and effectively. This improves the woman's quality of life and control population growth [9].

One of the factors that influence the use of Family Planning and other reproductive health services is client satisfaction with healthcare services. Users' satisfaction has been studied extensively at the global level and a number of determinants, including accessibility to health services, continuity of care, consultation time, waiting time, and provider/client relationship, have been identified as key factors correlated with satisfaction levels [8] [10]. Failure to address these quality determinants might be more costly than most other service improvements strategies would be [11].

Any conceptualization of quality encompasses both objective and subjective components. Objectively, products or services should meet or surpass standards of safety, proper function, cleanliness and otherwise general excellence. This is often referred to as quality control, quality assurance or "medical" quality, and it 
depends mainly on providers' perspectives [11].

In the past, most efforts to improve quality focused on these medical issues. In recent years, however, the subjective side of quality has also been recognized as vital, and clients' opinions, particularly, their degree of satisfaction are seen as essential to understanding quality care. A similar trend in evaluation has increased efforts to measure the subjective aspects of quality. Given the importance of client satisfaction both as an outcome and as an indicator; simple methodologies to measure satisfaction can play an important role in broader efforts to evaluate quality of care [11] [12] [13]. Patient satisfaction is measured over a wide range of health service dimensions, including availability, accessibility and convenience of services, technical competence of the providers and interpersonal skills(referred to as superstructure) and the physical environment where services are delivered (otherwise referred to as infrastructure). These are the articles of social marketing of contraceptive products [14].

Private-sector driven companies in developed countries (whether health-related or not) have, for a long time, recognized that a focus on customer satisfaction makes a good business sense. Satisfied clients make repeat purchases, become loyal to a particular brand, hence a continuation of use. Conversely, dissatisfied clients share negative experiences and are far less likely to return to buy the products or use the service in future, hence a discontinuation of use [11].

Furthermore, less than $30 \%$ of clients who experience quality related problems complain directly to the provider of the product or service and only $1 \%-5 \%$ of complaints reach the headquarters level [11]. These underscore the importance of getting it right at family planning clinics.

One principal determinant of uptake and continued utilization of family planning services is overall client satisfaction with the services provided. Client exit interviews conducted after the client had received services provides an opportunity to obtain information from the client's perception of service she received [8] [15].

The contraceptive prevalence rate in the hub of the study is $8.5 \%$ [16], which is low compared to Ghana with 23\% [17]. The overall current prevalence rate for contraceptive use in Nigeria is approximately $13 \%$ [18]. Therefore improved attitude/counselling to our clients will impact positively and promote uptake of our contraceptive services which would in turn go a long way in reducing our maternal mortality and morbidities associated with unplanned/unwanted pregnancies.

Hence, this study seeks to evaluate clients' satisfaction in family planning services in Port Harcourt, implication for continued use and uptake of various contraceptive methods.

\section{Materials and Methods}

Rivers state is made up of 23 local government areas (LGAs). Port Harcourt is the main city and capital of Rivers State as well as one of the local governments. This name is often used loosely to describe/include all the towns in Port Har- 
court LGA and its sounding towns in obio-akpor LGA where The University of Port Harcourt Teaching Hospital (UPTH) is actually domiciled.

The Family planning clinics serves both new acceptors and continuing users daily from Monday to Friday. Follow-up appointment is given to clients based on the duration of refill for each method in use while a 2 week appointment is given to the new clients.

A descriptive cross-sectional study design was used. The study population were clients who patronized the family planning service delivery points of The University of Port Harcourt Teaching Hospital and ten other randomly selected primary health care facilities in 0bio Akpor and Port Harcourt LGAs between $18^{\text {th }}$ of June 2018 and $18^{\text {th }}$ of July 2018. There were no exclusion criteria except for clients who refused consent during the period of data collection.

The prevalence of $85 \%$ was gotten from a similar study done by Kaoje et al. [15]. The sample size was determined using the formula

$$
n=\frac{Z^{2} P(P-1)}{D^{2}}
$$

where $Z$ is 1.96 (S.D at $95 \%$ confidence interval) and $D$ is 0.05 . A sample size of 195 was gotten.

An interviewer-administered exit questionnaire was designed by the researchers and was pretested for validity and reliability and used to collect data from the respondents. An exit interview was conducted after the client had completed all clinic procedures. Research assistants were selected and adequately trained to ensure adequacy and accuracy of the information collected during the interviews. No health service personnel of any of these family planning units were involved in the data collection. The interview was conducted at the reception of the health facility, or where available, a more remote compartment in the facility, in order to minimize bias from facility personnel.

Ethical approval for the conduct of the study was obtained from the University of Port Harcourt Teaching Hospital Research Ethics Committee and in addition, individual informed consent was also obtained from each respondent.

Socio-demographic characteristics of respondents, clinic factors (waiting time, clinic working environment, opportunity to ask question and availability and accessibility of family planning products among others) and client satisfaction were extracted. Client level of satisfaction was determined by asking whether they were satisfied with the services received or not, and then a direct assessment of four levels of satisfaction (very satisfied, somewhat satisfied, somewhat dissatisfied, and very dissatisfied). However, for the ease of binary logistic analysis, the levels were merged and categorized into satisfaction or dissatisfaction (not satisfied).

Data collected were analyzed using statistical package for the social science version 22.0. Mean and standard deviation were determined for normally distributed continuous variables while frequencies and percentages were carried out on categorical variables. The results were presented in tables and chart. $P$ value 
was set at $<0.05$ at a confidence interval of $95 \%$. Data was further subjected to logistic binary regression analysis and Odds ratio (O.R) deduced at the same confidence interval.

\section{Results}

\subsection{Socio-Demographic Characteristics}

Table 1 showed the socio-demographic characteristics of these participants.

The findings from this study have a two phase out-look: the socio-dermographic characteristics of the respondents and outcome of determinants of satisfaction in a contraceptive product.

Out of the 195 women involved in the study, 139 (71.3\%) were within the age bracket 21 to 40 years. All of the women were married except for 1 who was divorced. More than half of the women were multiparous, 152 (77.9\%). A good number of the participants (40\%), were business women. See Table 1.

\subsection{Access to Family Planning Information}

Healthcare providers accounted for $41.5 \%$ of FP information, peer group was

Table 1. Socio-demographic characteristics.

\begin{tabular}{|c|c|c|}
\hline Variables & Frequency (n) & Percentage \\
\hline \multicolumn{3}{|l|}{ Age } \\
\hline$\leq 20$ & 0 & 0 \\
\hline $21-30$ & 33 & 16.9 \\
\hline $31-40$ & 106 & 54.4 \\
\hline$\geq 41$ & 56 & 28.7 \\
\hline Total & 195 & 100 \\
\hline \multicolumn{3}{|l|}{ Parity } \\
\hline Nullipara & 2 & 1.0 \\
\hline Primipara & 1 & 0.5 \\
\hline Multipara & 152 & 78.0 \\
\hline Grandmultipara & 40 & 20.5 \\
\hline Total & 195 & 100 \\
\hline \multicolumn{3}{|l|}{ Level of education } \\
\hline Primary & 15 & 7.7 \\
\hline Secondary & 74 & 37.9 \\
\hline Tertiary & 106 & 54.4 \\
\hline Total & 195 & 100 \\
\hline \multicolumn{3}{|l|}{ Occupation } \\
\hline Business & 78 & 40.0 \\
\hline Civil servants & 61 & 31.3 \\
\hline Housewives & 45 & 23.1 \\
\hline Students/corpers & 11 & 5.6 \\
\hline Total & 195 & 100 \\
\hline
\end{tabular}


$29.2 \%$, and neighbours in $19.0 \%$ of respondents. The media contributed only $3.6 \%$. The implant contraceptive was the most commonly requested FP method (34.6\%) and intrauterine device $31.0 \%$.

\subsection{Waiting Times for Consultation}

The study showed that $148(87.1 \%)$ of the clients were attended to quickly and the time it took to receive the FP method chosen is shown in Figure 1. Waiting time was significantly associated with satisfaction $(p=0.000)$ as shown in Table 2 .

\subsection{Interactions between Providers and Family Planning Users}

All the women said they were treated in a friendly and respectful way. However, greater percentage of the women $(79.0 \%)$ did not know the name of the staff that attended to them.

A larger proportion, $80 \%$ of the women were okay with the clinic hours, while the rest found it not too convenient. The dissatisfaction in the clinic hours was noticed more in the business women and the civil servants. Respectful treatment and convenience of clinic hours was significantly associated with satisfaction clinic hours, $p=0.00$.

Concerning the time spent on counselling, majority (83.1\%) of the respondents were satisfied; but $22.6 \%$ of them felt it was a one sided discussion as they felt that the health worker dominated most of the discussion. However $77.4 \%$ of the clients said they had a balanced discussion. With reference to the responsiveness of the health workers about their concerns over some contraceptive methods, $86.6 \%$ of the clients were satisfied with the response of the health

80

70

60
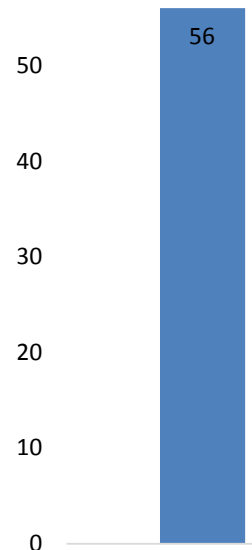

56

30 MINUTES
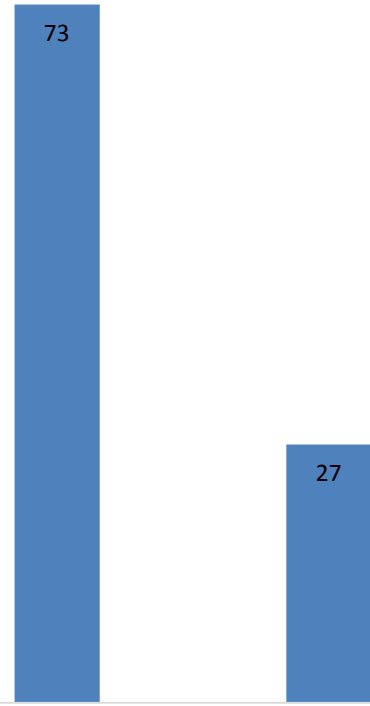

$>2$ HOURS

Figure 1. Waiting time of client. 
Table 2. Factors affecting satisfaction.

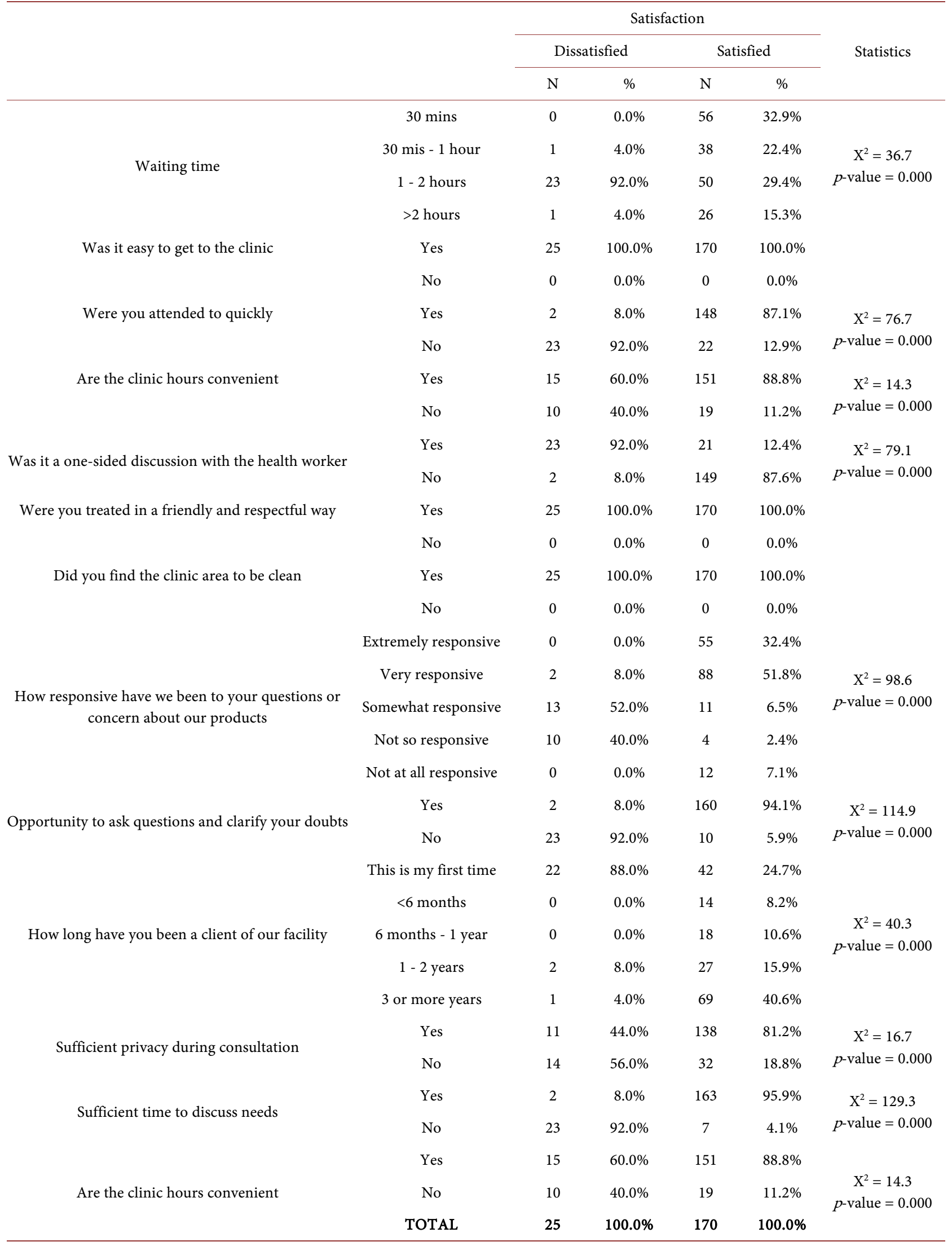


workers. The quality of the counselling was significantly associated with client satisfaction in our family planning delivery, $p$ value $=0.00$.

\subsection{Response of Clients' Satisfaction}

All the respondents had easy access to the family planning clinic. All the women found the clinic area clean. Majority of the clients have patronized the clinics for more than a year.

On the likelihood of recommending the facility to another person (graded in a scale of $0-4,4$ representing a very strong likelihood), $62.6 \%$ of the women gave a score of $4 ; 17.6 \%$ chose 3 . Only $19.8 \%$ of the women chose either 1 or 2 , or did not respond to this particular question.

Overall, $87.2 \%$ of the women were satisfied with the services provided and said they would visit the facility again and would also recommend the facility to other people.

Satisfaction was significantly associated with the waiting time, privacy during consultation, discussion with the health worker and number of years of use of the family planning clinic, with $P$-values $=0.000$ each. However using logistic binary regression, opportunity to ask questions and clarify doubts and how well do the family planning methods and services (opportunity to ask questions and clarify doubt) put together meet your needs, were the only factors that were found to be statistically significant with $p$-values of 0.008 and 0.018 respectively. Furthermore, the odds of having satisfaction with family planning delivery services was found to be higher with convenience of the clinic time [O.R $=1.4$ (0.1 17.1)], privacy during consultation [O.R $=1.7(0.2-13.5)]$ and duration of use of the facility $[\mathrm{O} . \mathrm{R}=1.3(0.7-2.5)]$ as shown in Table 3 .

\section{Discussion}

Over the decades, quality care and hence client satisfaction are fast becoming a global trend; gained increasing attention generally, and are of great concern to health care managers/policymakers and providers as well users [1] [2] [3] [15]. Client satisfaction evaluation provides the only means for clients to express themselves on the services received and also an opportunity for the program to

Table 3. Regression model on determinants of client satisfaction.

\begin{tabular}{|c|c|c|c|c|c|c|c|c|}
\hline & \multirow{2}{*}{ B } & \multirow{2}{*}{ S.E. } & \multirow{2}{*}{ Wald } & \multirow{2}{*}{$\mathrm{Df}$} & \multirow{2}{*}{$p$-value } & \multirow{2}{*}{ Odd Ratio } & \multicolumn{2}{|c|}{$95 \%$ C.I. for O. $\mathrm{R}$} \\
\hline & & & & & & & Lower & Upper \\
\hline Are the clinic hours convenient & 0.339 & 1.276 & 0.071 & 1 & 0.790 & 1.404 & 0.115 & 17.133 \\
\hline Opportunity to ask questions and clarify your doubts & -3.530 & 1.328 & 7.070 & 1 & 0.008 & 0.029 & 0.002 & 0.395 \\
\hline Did you have sufficient privacy during your consultation & 0.515 & 1.067 & 0.233 & 1 & 0.629 & 1.673 & 0.207 & 13.541 \\
\hline How well do our products and service meet your needs & -2.211 & 0.936 & 5.575 & 1 & 0.018 & 0.110 & 0.017 & 0.687 \\
\hline How long have you been a client of our facility & 0.283 & 0.316 & 0.803 & 1 & 0.370 & 1.328 & 0.714 & 2.468 . \\
\hline Constant & 11.258 & 3.707 & 9.222 & 1 & 0.002 & $77,475.170$ & & \\
\hline
\end{tabular}


be evaluated by the users based on their own perception [15] [19]-[24]. It is therefore, a valuable input to guide modifications and improvement in service delivery, identify what clients want as opposed to what provider or healthcare managers think the clients want.

This study explored the role the individual factors and service provision factors have on women's satisfaction with family planning services in Port Harcourt. The study showed that the majority $87.2 \%$ of the women attending the family planning clinics in Port Harcourt were satisfied with the quality of services rendered. Though this is good and is in agreement with some other studies [10] [15], the target should tend towards every women being satisfied. Factors that may have caused the increased level of satisfaction despite long waiting hours were, the sanitary condition of the clinic environment, provider/client interaction, availability and affordability of contraceptives offered and the easy access to the clinic. They were all significantly associated with client satisfaction.

The dissatisfaction level in this study was far lower than those found in other studies done by Argago et al. 2015, where it was 24.7\% [21] and Baa in Ethiopia $2017,55 \%$ [1]. This observation is not surprising considering the attention of the Rivers State government on primary health care delivery.

Even the $12.8 \%$ of the respondents that had dissatisfaction with the services rendered expressed the desire to visit the facility again and are also willing to refer friends and family members to these family planning clinics. This possibly shows that the level of dissatisfaction is not marked among other reasons. However, the long awaiting time noted in a significant number of respondents and complaint of convenience of clinic timing is worrisome and must be addressed.

Findings from a previous study suggest that users of healthcare services tend to value their interaction with the provider, and this contributes significantly to the user's satisfaction [10]. In this study, it was also noticed that the clients who had used family planning services in Port Harcourt for a longer period (more than 1 year), had greater level of satisfaction than first time users or less than 6 months users. This could be that returning clients have presumably had some experience and developed a relationship with the health care providers, enabling them to navigate inherent barriers such as long waiting time, locating the different service points [14], as well as other services provided by the family planning clinic such as cervical cancer screening.

Also clients returning for clinical review or prescription refill/change, had relatively higher general satisfaction than those attending for the first time; a finding that is consistent with results from elsewhere. One possible explanation for greater satisfaction could be that returning patients are self-selected for high perceived satisfaction at this hospital but the perceptions of those who do not return possibly because of poor satisfaction are not captured. Nabbuye et al. 2014 and Al - Abri et al. 2011, demonstrated that satisfaction predicted patient's intention to return for the same service in future [12] [14]. 


\section{Conclusion}

Clients' satisfaction in family planning services in this study was high. However, waiting time was noted to be long. Therefore, as we aim at improving upon the level of satisfaction in the choice of contraceptive made by every woman, the long waiting time and the problem of timing of the clinics must be addressed. The ultimate implication is that this high level of clients' satisfaction will lead to a continued use and the desired improvement in contraceptive uptake generally.

\section{Recommendations}

More studies are needed in this direction. Inclusion of weekends for family planning clinic consultation will definitely improve uptake of family planning methods. Training and retraining of family planning providers are to further strengthen their communication skills to meet the individual needs of the clients and match the challenging demands of our time.

\section{Study Limitation}

The inability of this study to make conclusion on Rivers State in general (based on the limited area of data collection) is a limitation, to some extent, to health care policy makers in Rivers State, Nigeria. Futher study involving samples from the whole of Rivers State is needed.

\section{Conflicts of Interest}

The authors declare no conflicts of interest regarding the publication of this paper.

\section{References}

[1] Tessema, G.A., Gomersall, J.S., Mahmood, M.A. and Laurence, C.O. (2016) Factors Determining Quality of Care in Family Planning Services in Africa: A Systematic Review of Mixed Evidence. PLoS ONE, 11, e0165627. https://doi.org/10.1371/journal.pone.0165627

[2] Starbird, E., Norton, M. and Marcus, R. (2016) Investing in Family Planning: Key to Achieving the Sustainable Development Goals. Global Health: Science and Practice, 4, 191-210. https://doi.org/10.9745/GHSP-D-15-00374

[3] Baa, W. (2017) Assessment of Client Satisfaction on Family Planning Services Utilization in Wonji Hospital, Ethiopia 2016. JBR Journal of Clinical Diagnosis and Research, 5, 137. https://doi.org/10.4172/2376-0311.1000137

[4] Oranu, E.O. and Ojule, J.D. (2018) A Decade of Jadelle Subdermal Implant Contraception in a Tertiary Health Institution in Port Harcourt, Southern Nigeria. JBM, 6, 123-130. https://doi.org/10.4236/jbm.2018.63010

[5] Zureick-Brown, S., Newby, H., Chou, D., Mizoguchi, N., Say, L., Suzuki, E., et al. (2013) Understanding Global Trends in Maternal Mortality. International Perspectives on Sexual and Reproductive Health, 39, 32-41. https://doi.org/10.1363/3903213

[6] Etukudo, I.W. (2015) Information as Determinant of Utilization of Family Planning 
Services in Rural Akwa Ibom State of South-South Nigeria. MJSS, 6, 445. https://doi.org/10.5901/mjss.2015.v6n4s1p445

[7] Tafese, F., Woldie, M. and Megerssa, B. (2013) Quality of Family Planning Services in Primary Health Centers of Jimma Zone, Southwest Ethiopia. Ethiopian Journal of Health Sciences, 23, 245-254. https://doi.org/10.4314/ejhs.v23i3.7

[8] Bintabara, D., Ntwenya, J., Maro, I.I., Kibusi, S., Gunda, D.W. and Mpondo, B.T. (2018) Client Satisfaction with Family Planning Services in the Area of High Unmet Need: Evidence from Tanzania Service Provision Assessment Survey, 2014-2015. Reproductive Health, 15, 127-132. https://doi.org/10.1186/s12978-018-0566-8

[9] Blackstone, S.R. and Iwelunmor, J. (2017) Determinants of Contraceptive Use among Nigerian Couples: Evidence from the 2013 Demographic and Health Survey. Contraception and Reproductive Medicine, 2, 9. https://doi.org/10.1186/s40834-017-0037-6

[10] Chavane, L., Dgedge, M., Bailey, P., Loquiha, O., Aerts, M. and Temmerman, M. (2016) Assessing Women's Satisfaction with Family Planning Services in Mozambique. Journal of Family Planning and Reproductive Health Care, 2015, Article ID: 101190. https://doi.org/10.1136/jfprhc-2015-101190

[11] Williams, T., Schutt-Aine, J. and Cuca, Y. (2000) Measuring Family Planning Service Quality through Client Satisfaction Exit Interviews. International Family Planning Perspectives, 26, 63-71. https://doi.org/10.2307/2648269

[12] Nabbuye-Sekandi, J., Makumbi, F.E., Kasangaki, A., Kizza, I.B., Tugumisirize, J., Nshimye, E., et al. (2011) Patient Satisfaction with Services in Outpatient Clinics at Mulago Hospital, Uganda. International Journal for Quality in Health Care, 23, 516-523. https://doi.org/10.1093/intqhc/mzr040

[13] Mosadeghrad, A.M. (2014) Factors Affecting Medical Service Quality. Iranian Journal of Public Health, 43, 210-220. https://doi.org/10.15171/ijhpm.2014.65

[14] Al-Abri, R. and Al-Balushi, A. (2014) Patient Satisfaction Survey as a Tool towards Quality Improvement. Oman Medical Journal, 29, 3-7.

https://doi.org/10.5001/omj.2014.02

[15] Kaoje, U.A. (2015) Determinants of Client Satisfaction with Family Planning Services in Government Health Facilities in Sokoto, Northern Nigeria. Sahel Medical Journal, 18, 20-26. https://doi.org/10.4103/1118-8561.152154

[16] Alegbeleye, J.O. and John, C.O. (2016) Family Planning Practice in a Nigerian Tertiary Hospital: A Five Year Review. BJMMR, 18, 1-9. https://doi.org/10.9734/BJMMR/2016/28941

[17] Wilson, H.W., Ameme, D.K. and Ilesanmi, O.S. (2017) Contraceptive Methods Accessed in Volta Region, Ghana, 2009-2014. International Scholarly Research Notices, 4, 32-41. https://doi.org/10.1155/2017/7257042

[18] Emechebe, E. (2016) Complications of Induced Abortion: Contribution to Maternal Mortality in a Tertiary Center of a Low Resource Setting. Saudi Journal for Health Sciences, 5, 34-38. https://doi.org/10.4103/2278-0521.182864

[19] Abdel-Tawab, N. and Roter, D. (2002) The Relevance of Client-Centered Communication to Family Planning Settings in Developing Countries: Lessons from the Egyptian Experience. Social Science \& Medicine, 54, 1357-1368. https://doi.org/10.1016/S0277-9536(01)00101-0

[20] Tuoane, M., Madise, N.J. and Diamond, I. (2004) Provision of Family Planning Services in Lesotho. International Family Planning Perspectives, 30, 77-86.

https://doi.org/10.1363/3007704 
[21] Argago, T.G., Hajito, K.W. and Kitila, S.B. (2015) Clients Satisfaction with Family Planning Services and Associated Factors among Family Planning Users in Hossana Town Public Health Facilities, South Ethiopia: Facility-Based Cross-Sectional Study. International Journal of Nursing and Midwifery, 7, 74-83.

https://doi.org/10.5897/IJNM2015.0163

[22] Baruda, F., Dibaba, Y., Tamiru, D. and Jisha, H. (2018) Satisfaction with Family Planning Services in Southern Ethiopia. African Journal of Midwifery and Women's Health, 12, 44-49. https://doi.org/10.12968/ajmw.2018.12.1.44

[23] Ahanonu, E.L. (2014) Attitudes of Healthcare Providers towards Providing Contraceptives for Unmarried Adolescents in Ibadan, Nigeria. Journal of Family and Reproductive Health, 8, 33-40.

[24] Mohamed, S.A., Mohamed, A.G. and Arief, A.F. (2017) Women Satisfaction with Family Planning Services in Maternal and Child Health Centers, Assiut City, Egypt. AJN The American Journal of Nursing, 5, 79-85.

https://doi.org/10.12691/ajnr-5-3-2 